\title{
The effect of Cistus incanus herbal tea supplementation on oxidative stress markers and lipid profile in healthy adults
}

\author{
Agnieszka Kuchta ${ }^{1}$, Agnieszka Konopacka ${ }^{2}$, Krzysztof Waleron $^{2}$, Agnieszka Viapiana ${ }^{3}$, \\ Marek Wesołowski ${ }^{3}$, Kamil Dąbkowski ${ }^{1}$, Agnieszka Ćwiklińska ${ }^{1}$, \\ Agnieszka Mickiewicz ${ }^{4}$, Anna Śledzińska ${ }^{5}$, Ewa Wieczorek ${ }^{1}$, \\ Anna Gliwińska ${ }^{1}$, Barbara Kortas-Stempak ${ }^{1}$, Maciej Jankowski ${ }^{1}$ \\ ${ }^{1}$ Department of Clinical Chemistry, Medical University of Gdansk, Poland \\ ${ }^{2}$ Department of Pharmaceutical Microbiology, Medical University of Gdansk, Poland \\ ${ }^{4}$ Department of Analytical Chemistry, Medical University of Gdansk, Poland \\ ${ }^{4} 1^{\text {st }}$ Department of Cardiology, Medical University of Gdansk, Poland \\ ${ }^{5}$ Department of Therapeutic Drug Monitoring and Pharmacogenetics, Medical University of Gdansk, Poland
}

\begin{abstract}
Background: Oxidative stress and dyslipidemia play a critical role in the development of cardiovascular disease (CVD). Regular intake of polyphenol-rich diets is associated with a reduced risk of CVDs. Methods: The present study was a pilot study with 24 healthy volunteers and was designed to determine if a 12-week administration of Cistus incanus herbal tea, containing phenolic acids and flavonoids, reduces cardiovascular risk factors including oxidative stress and dyslipidemia in healthy adults. Phenolic compounds profile and antibacterial activity of Cistus incanus infusion were also measured. Results: Herbal infusion led to improvement in lipid profile by increase $(\Delta 4 \%, p=0.033)$ high-density lipoprotein cholesterol concentration and decrease triglyceride $(\Delta 14 \%, p=0.013)$ concentrations. In addition, the Cistus incanus diet was associated with decreased serum concentrations of malondialdehyde $(\Delta 16 \%, p<0.01)$ and advanced oxidation protein products $(\Delta 18 \%, p<0.001)$.

Conclusions: Cistus incanus administration decreases cardiovascular risk factors including oxidative stress and dyslipidemia and this action supports the idea of using Cistus incanus tea on a daily basis as an effective dietary component for prevention of atherosclerotic CVD. (Cardiol J 2021; 28, 4: 534-542)

Keywords: Cistus incanus, lipid profile, oxidative stress markers
\end{abstract}

\section{Introduction}

Cistus incanus, a genus belonging to the family of Cistaceae, provides a rich source of polyphenols and various Cistus species herbal teas have been used in folk medicine for treatment of diarrhea, fever, and skin disorders. It also has antispasmodic, anti-inflammatory and antimicrobial agents [1]. Currently, numerous producers offer Cistus in- canus herbal infusion (Cistus tea) or dietary supplements consisting of this plant material, or extracts of it. These products are especially promoted with regard to a high content and diverse profile of polyphenolic substances with strong antioxidant activity [2]. It has been proposed that polyphenols can act as antioxidants by suppression of reactive species formation through enzyme inhibition or the sequestration of trace elements involved

Address for correspondence: Dr. Agnieszka Kuchta, Department of Clinical Chemistry, Medical University of Gdansk, ul. Dębinki 7, 80-211 Gdańsk, Poland, tel: +48 5834927 95, fax: +48 58341 23 05, e-mail: agnieszka.kuchta@gumed.edu.pl Received: 12.01.2019 Accepted: 14.02.2019

This article is available in open access under Creative Common Attribution-Non-Commercial-No Derivatives 4.0 International (CC BY-NC-ND 4.0) license, allowing to download articles and share them with others as long as they credit the authors and the publisher, but without permission to change them in any way or use them commercially. 
in the production of free radicals [3]. Reactive oxygen species are involved in pathogenesis of diverse human diseases which play a particular role in cardiovascular diseases $[4,5]$. Polyphenols are able to attenuate the oxidation of low-density lipoproteins (LDL), possess vasodilatory and antiinflammatory activity, and modulate lipid metabolism and apoptotic processes in endothelium [6]. It has been suggested that most of these effects are a consequence of the antioxidant properties of polyphenols; however, other mechanisms based on their interaction with molecular signaling pathways may be involved $[2,7]$.

Epidemiological studies provide evidence for an inverse relationship between the consumption of polyphenolic substance-rich foods and cardiovascular complications [8]; however, most of the epidemiological studies aimed at investigating cardiovascular benefits of polyphenols have concerned tea, red wine, coca and polyphenol-rich fruits such as grapes. Furthermore, although there are numerous studies evaluating the composition and antioxidant capacities of Cistus infusion, however, clinical studies focused on the influence of Cistus incanus on oxidation balance and cardiovascular risk factors are limited [9]. Thus, the purpose of the present study was to investigate the impact of a 3-month supplement of commercially available Cistus incanus tea on oxidative stress markers and lipid profile in healthy adults. Additionally, the phenolic compounds profile was determined as well as antibacterial activity of when using Cistus incanus aqueous infusions.

\section{Methods}

\section{Study subjects}

A total of 24 healthy adults were recruited for the study. All procedures performed in studies involving human participants were in accordance with the 1964 Helsinki declaration and were approved by the Medical Ethics Committee of Medical University of Gdansk. All participants provided written informed consent.

During the interview, sociodemographic and clinical information was collected. The sociodemographic data included age, and gender. Clinical variables included vascular risk factors: smoking status, alcohol intake, physical activity, lifestyle, and dietary habits. All participants were nonsmoking and were sedentary or moderately physically active (at least 2 times a week). All volunteers were instructed not to change their diet or physical activity during the study. The exclusion criteria were: chronic disease, current use of prescribed pharmaceuticals, intense physical activity (up to 3 times a week) and a body mass index (BMI) greater than $25 \mathrm{~kg} / \mathrm{m}^{2}$. The study period was 12 weeks, during which participants would intake a Cistus incanus infusion 3 times a day (portion of $2 \mathrm{~g}$ of dry tea per day reinfused 3 times in $250 \mathrm{~mL}$ of boiling water for $3 \mathrm{~min}$ ). Dietary compliance was assessed using daily study records completed by the participants.

\section{Analysis of blood samples from subjects}

The peripheral fasting blood samples were collected before (baseline) and after 6 and 12 weeks of Cistus incanus infusion administration. The serum was separated by centrifugation at $1000 \times \mathrm{g}$ for $15 \mathrm{~min}$ and stored at $-80^{\circ} \mathrm{C}$ pending analysis. Total cholesterol (TC) and triglycerides (TG) were measured by standard enzymatic colorimetric tests (Pointe Scientific Poland). High density lipoproteins (HDLs) were isolated by precipitation of apolipoprotein $\mathrm{B}$ (apoB)-containing lipoproteins with dextran sulfate $50000 / \mathrm{Mg}^{2+}$ reagent and HDL cholesterol (HDL-C) was determined enzymatically. LDL cholesterol (LDL-C) concentration was calculated using the Friedewald formula. Paraoxonase (PONase) and arylesterase (AREase) activities of paraoxonase-1 (PON-1) were measured based on paraoxon and phenyl acetate hydrolysis, respectively [10,11]. Malondialdehyde (MDA) concentration was analyzed by fluorescence spectroscopy using a modified thiobarbituric acidreactive substance [12]. Advanced oxidative protein product (AOPP) determination was performed based on spectrophotometric detection [13].

\section{Plant material}

The Cistus incanus herb was purchased from a manufacturer in Poland (herbal manufacture ASTRON Józef Tabor). According to the manufacture information, the shrub grows in the Mediterranean Region of Turkey around the city of Antalya, and the shrub's leaves are harvested from May to August.

\section{Determination of total polyphenols and antioxidant activity}

The leaves $(1.00 \mathrm{~g})$ were brewed with $100 \mathrm{~mL}$ of boiling and deionized water for $15 \mathrm{~min}$ and the procedure was repeated two times to finally produce the first, second and third infusion. The Folin-Ciocalteu method was used for total phenolic content (TPC) determination [14]. The method described in the European Pharmacopeia monograph for Betulae folium was used for total 
flavonoid content (TFC) determination [15]. The total phenolic acid content was determined using the spectrophotometric method with Arnov's reagent according to procedures described in the Polish Pharmacopoeia [16]. L-ascorbic acid (AA) was determined by spectrophotometric method [17].2,2-diphenyl-1-picrylhydrazyl radical (DPPH) scavenging assay [18] and ferric ion reducing antioxidant power (FRAP) assay [19] were used to determine the reducing antioxidant power of the Cistus incanus infusions.

Chromatographic analysis: HPLC conditions Before HPLC analysis, all the infusions were filtered through a $0.2 \mu \mathrm{m}$ nylon filter film (Mecherey, Nagel, Germany) and $20 \mu \mathrm{L}$ of the filtrate was injected into the HPLC system. Chromatographic separation and quantitation of phenolic compounds (gallic, caffeic, chlorogenic, syringic, vanillic, p-coumaric, elagic and ferulic acids, and rutin, isoquercetin, quercetin, myricetin, kaempferol, and luteolin 7-glucoside) were performed on a Hypersil Gold C18 column $(250 \times 4.6 \mathrm{~mm}$, $5 \mu \mathrm{m}$ particles, Thermo Scientific, Runcorn, UK) maintained at $35^{\circ} \mathrm{C}$, using acetonitrile $-0.2 \%$ trifluoroacetic acid solution and water $-0.2 \%$ trifluoroacetic acid solution as the mobile phase using a gradient program and monitoring system as previously described [20].

\section{Antibacterial activity}

A sample of Cistus incanus (2.5 g) was infused three times with $50 \mathrm{~mL}$ of boiling, deionised water for $15 \mathrm{~min}$ to produce the first, second, and third infusion. The minimal inhibitory concentration (MIC) and minimal bactericidal concentration $(\mathrm{MBC})$ of all the infusions were assessed by the micro-broth dilution method according to the EUCAST (European Committee for Antimicrobial Susceptibility Testing) and CLSI (Clinical and Laboratory Standards Institute) reference procedures. Assays were carried out against selected reference and clinical strains Gram-positive: Staphylococcus aureus ATCC 6538, methicillin-resistant Staphylococcus aureus 12,673 (clinical isolates), Staphylococcus epidermidis ATCC 14,990, methicillin-resistant Staphylococcus epidermidis (clinical isolates), Streptococcus pneumoniae (clinical isolates), Bacillus subtilis ATCC 6633, and Gram-negative bacteria Escherichia coli ATCC 8739. Clinical isolates were obtained from St. Albert Specialist Hospital in Gdansk (Independent Public Health Care Facility in Gdansk, Poland).

\section{Statistical analysis}

Statistical analysis was performed using the Statistica software package (STATISTICA 12.0 Statsoft Poland). The Shapiro-Wilk test was used to establish data distributions. Continuous variables were expressed as a mean \pm standard deviation or median with $25^{\text {th }}$ and $75^{\text {th }}$ percentiles (interquartile range $[I Q R])$. Potential differences among the results were analyzed using a repeated-measures ANOVA with the Tukey multiple comparison test for parametric variables and with the Friedman test for non-parametric data. Statistical significance was set at $\mathrm{p}<0.05$.

\section{Results}

The study participants were aged between 23 and 25 years old ( 21 females and 3 males) with a body mass index (BMI) of $21.3 \pm 0.6 \mathrm{~kg} / \mathrm{m}^{2}$. There were no significant differences in BMI during the 12 -week period of dietary modification.

\section{Lipid profile and serum oxidative stress parameters}

Analysis of the lipid profile revealed a significant increase in HDL-C concentration ( $47 \pm 9$ vs. $50 \pm 9 \mathrm{mg} / \mathrm{dL} ; \mathrm{p}=0.033)$ and a decrease in $\mathrm{TG}$ levels $(71 \pm 23$ vs. $60 \pm 24 \mathrm{mg} / \mathrm{dL} ; \mathrm{p}=0.013)$, there were no changes in the concentration of TC and LDL-C over 12 weeks of follow up (Fig. 1). The concentrations of serum oxidative stress markers - MDA and AOPP were measured before and after 6 and 12 weeks of Cistus incanus herbal tea supplementation. A reduction of about $16 \%$ in MDA concentration $(20 \pm 5.5$ vs. $15 \pm 4.9 \mu \mathrm{mol} / \mathrm{L}$; $\mathrm{p}<0.01)$ and $18 \%$ in AOPP concentration (66 \pm \pm 18 vs. $53 \pm 17 \mu \mathrm{mol} / \mathrm{L} ; \mathrm{p}<0.001)$ after the first 6 weeks of Cistus incanus intake was observed (Fig. 2). The following 6 weeks of supplementation showed no further significant changes in concentrations of MDA $(15 \pm 4.9$ vs. $15 \pm 4.5 \mu \mathrm{mol} / \mathrm{L})$ and AOPP $(53 \pm 17$ vs. $54 \pm 16 \mu \mathrm{mol} / \mathrm{L})$. There was no significant effect of Cistus infusion on PON-1 activities, measured both toward paraoxon and phenyl acetate as substrates (Table 1).

\section{Phenolic content and antioxidant capacity}

Total phenolic acids (TPC), flavonoids (TFC), phenolic acids (TPAC) and L-ascorbic acid (AA) contents in multiple aqueous extractions of $\mathrm{Cis}$ tus incanus were determined, the results are presented in Table 2 . Analysis of variance and the Duncan multiple range test indicate a significant 


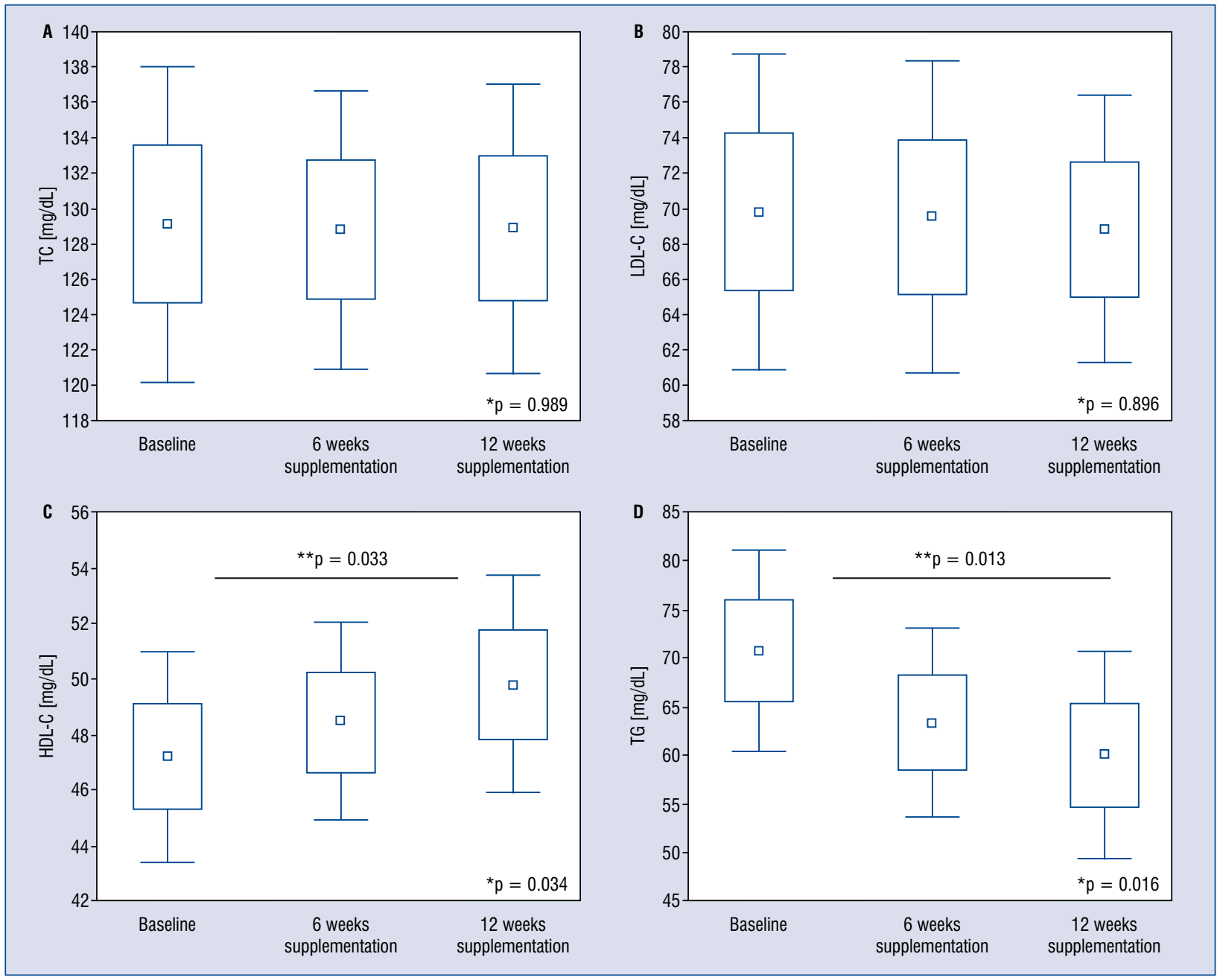

Figure 1. Serum concentrations of total cholesterol (TC) (A), low density lipoprotein cholesterol (LDL-C) (B), high density lipoprotein cholesterol (HDL-C) (C), and triglycerides (TG) (D); at baseline, after 6- and 12-weeks supplementation with Cistus incanus herbal tea. All values represent means \pm standard error. Data were analyzed using a repeatedmeasures ANOVA $\left({ }^{*}\right)$ with the Tukey post hoc test $\left({ }^{* *}\right)$ to determine where differences existed.

influence of multiple extractions $(\mathrm{p}<0.05)$ on TPC, TFC, TPAC, and AA. The effects of multiple extractions on the phenolic acids and flavonoids content of Cistus infusions are presented in Tables 3 and 4, respectively. Among phenolic acids the most abundant was gallic acid. Caffeic and vanilic acids were determined only in the first extraction, while chlorogenic, syringic and ferulic acids were not found. In the case of flavonoids, myricetin and isoquercetin were the most abundant, while keampferol was not determined. According to the TPC, TFC, TPAC and AA the content of phenolic acids and flavonoids also gradually decreased and the lowest content was obtained in the third extract of Cistus infusions. The antioxidant capacities of Cistus incanus evaluated by DPPH and FRAP as- says exhibited a gradual decrease and the lowest activity was obtained in the third extract of Cistus infusions (Table 5).

\section{Antibacterial activity}

To investigate the possible antibacterial activity of aqueous Cistus incanus, Gram-positive and Gram-negative bacteria strains were used. The values of MIC and MBC are shown in Table 6. For all Gram-positive bacteria, the MIC value was $4 \mathrm{mg} / \mathrm{mL}$ and the $\mathrm{MBC}$ ranged from 8 to $32 \mathrm{mg} / \mathrm{mL}$, suggesting a bacteriostatic effect. There was no difference in antimicrobial activity of the extracts between successive infusions. No activity was demonstrated against Gram-negative bacteria in the tested concentration range. 

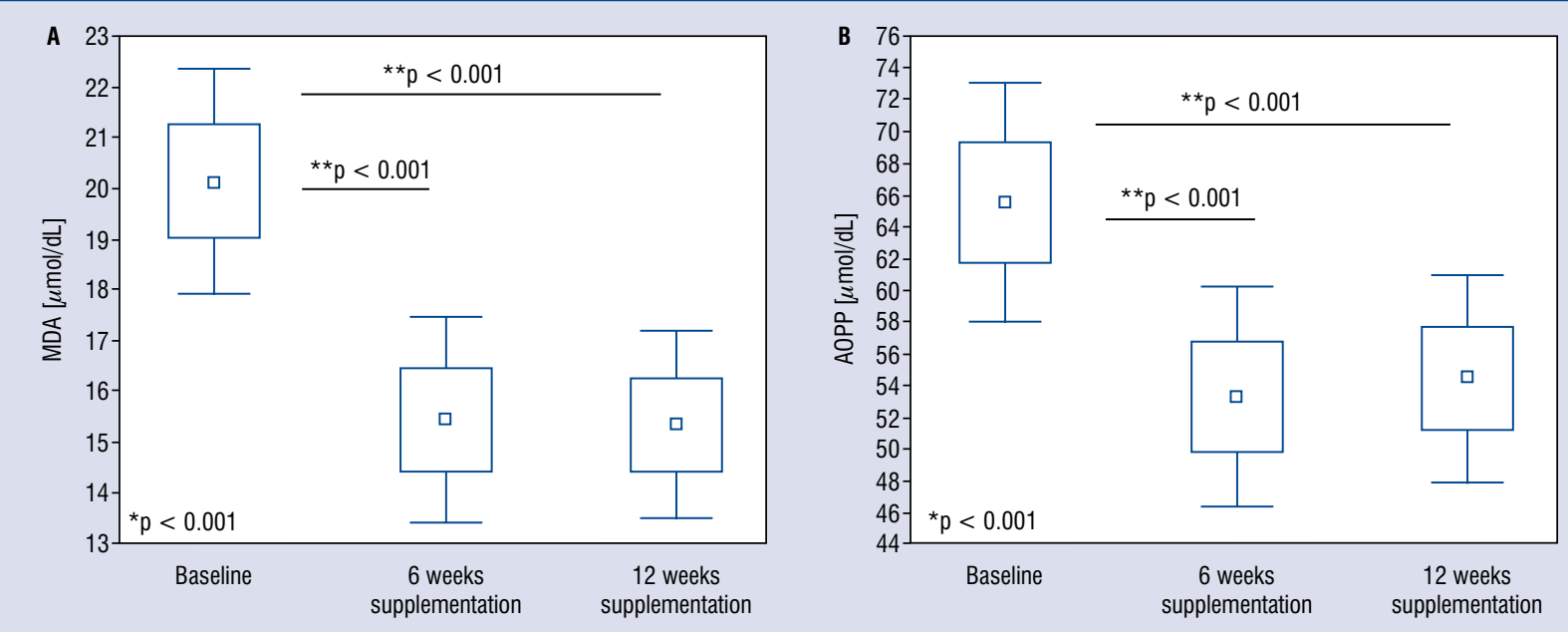

Figure 2. Serum concentrations of malondialdehyde (MDA) (A) and advanced oxidative protein products (AOPP) (B); at baseline, after 6- and 12-weeks supplementation with Cistus incanus herbal tea. All values represent means \pm \pm standard error. Data were analysed using a repeated-measures ANOVA $\left({ }^{*}\right)$ with the Tukey multiple comparison test $\left({ }^{*}\right)$ to determine where differences existed.

Table 1. Paraoxonase-1 (PON-1) activity before, after 6 and 12 weeks of Cistus incanus herbal tea supplementation.

\begin{tabular}{|c|c|c|c|c|c|c|}
\hline \multirow[t]{2}{*}{ PON-1 activity } & \multicolumn{2}{|c|}{ Baseline } & \multicolumn{2}{|c|}{6 weeks } & \multicolumn{2}{|c|}{12 weeks } \\
\hline & Median & IQR & Median & IQR & Median & IOR \\
\hline Paraoxonase [U/L] & 104 & $75-187$ & 94 & 73-193 & 102 & 78-195 \\
\hline Arylesterease $[\mathrm{kU} / \mathrm{L}]$ & 211 & $172-236$ & 211 & $176-234$ & 206 & $158-233$ \\
\hline
\end{tabular}

*Potential differences among the results were analyzed using the Friedman test; IQR — interquartile range

Table 2. Total phenolic (TPC) and flavonoids (TFC), phenolic acids (TPAC) and L-ascorbic acid (AA) contents in Cistus incanus multiple aqueous extractions.

\begin{tabular}{lcccc} 
Extraction & $\begin{array}{c}\text { TPC } \\
{[\mathrm{mg} \mathrm{GAE} / \mathbf{g ~ d w}]}\end{array}$ & $\begin{array}{c}\text { TFC } \\
{[\mathrm{mg} \mathrm{OE} / \mathbf{g ~ d w}]}\end{array}$ & $\begin{array}{c}\text { TPAC } \\
{[\mathrm{mg} \mathrm{CAE} / \mathbf{g ~ d w}]}\end{array}$ & $\begin{array}{c}\text { AA } \\
{[\mathrm{mg} \mathrm{AA} / \mathbf{g ~ d w}]}\end{array}$ \\
\hline First & $98.5 \pm 1.3$ & $2.5 \pm 0.4$ & $10.9 \pm 0.9$ & $0.86 \pm 0.05$ \\
Second & $85.3 \pm 1.1$ & $1.8 \pm 0.5$ & $9.0 \pm 1.1$ & $0.76 \pm 0.02$ \\
Third & $78.5 \pm 1.0$ & $1.6 \pm 0.9$ & $7.7 \pm 1.8$ & $0.67 \pm 0.03$ \\
\hline
\end{tabular}

Values are expressed as means \pm standard deviation $(\mathrm{n}=3) ; \mathrm{mg} \mathrm{GAE} / \mathrm{g} \mathrm{dw}-\mathrm{mg}$ of gallic acid equivalent per gram dry weigh; mg QE/g dw - $\mathrm{mg}$ of quercetin equivalent per gram dry weight; $\mathrm{mg} \mathrm{CAE} / \mathrm{g} \mathrm{dw}$ - $\mathrm{mg}$ of caffeic acid equivalent per gram dry weight; $\mathrm{mg}$ AA/g/dw — $\mathrm{mg}$ of L-ascorbic acid per gram dry weight

Table 3. The contents of phenolic acids-gallic (GA), caffeic (CA), chlorogenic (CGA), syringic (SA), vanillic (VA), para-coumaric (pCA), elagic (EA), ferulic ( $F A)$ in Cistus incanus multiple aqueous extractions.

\begin{tabular}{lcccccccc}
\hline Extraction & $\begin{array}{c}\text { GA } \\
{[\mu \mathbf{g} / \mathbf{g ~ d w}]}\end{array}$ & $\begin{array}{c}\text { CA } \\
{[\mu \mathbf{g} / \mathbf{g ~ d w}]}\end{array}$ & $\begin{array}{c}\text { CGA } \\
{[\mu \mathbf{g} / \mathbf{g ~ d w}]}\end{array}$ & $\begin{array}{c}\text { SA } \\
{[\mu \mathbf{g} / \mathbf{g ~ d w}]}\end{array}$ & $\begin{array}{c}\text { VA } \\
{[\mu \mathbf{g} / \mathbf{g ~ d w}]}\end{array}$ & $\begin{array}{c}\text { pCA } \\
{[\mu \mathbf{g} / \mathbf{g ~ d w}]}\end{array}$ & $\begin{array}{c}\text { EA } \\
{[\mu \mathbf{g} / \mathbf{g ~ d w}]}\end{array}$ & $\begin{array}{c}\text { FA } \\
{[\mu \mathbf{g} / \mathbf{g ~ d w}]}\end{array}$ \\
\hline First & $496.4 \pm 3.1$ & $38.5 \pm 1.4$ & ND & ND & $26.2 \pm 1.2$ & $126.5 \pm 2.3$ & $243.6 \pm 2.7$ & ND \\
Second & $340.3 \pm 2.4$ & ND & ND & ND & ND & $76.1 \pm 2.0$ & $185.3 \pm 1.8$ & ND \\
Third & $260.6 \pm 2.1$ & ND & ND & ND & ND & $60.2 \pm 1.0$ & $143.4 \pm 1.1$ & ND \\
\hline
\end{tabular}

Values are expressed as means \pm standard deviation $(n=3) ; N D$ - not detectable

Limits of detection $[\mu \mathrm{g} / \mathrm{mL}]$ : $\mathrm{CA}-3.2, \mathrm{CGA}-2.0, \mathrm{SA}-3.8$, VA $-7.3, \mathrm{FA}-2.9$ 
Table 4. The content of flavonoids: rutin (RUT), isoquercetin (IsoQ), quercetin (QUE), myricetin (MYR), kaempferol (KAE), 7-luteolin glucoside (L-7gl) in Cistus incanus multiple aqueous extractions.

\begin{tabular}{lcccccc}
\hline Extraction & $\begin{array}{c}\text { RUT } \\
{[\mu \mathrm{g} / \mathbf{g ~ d w}]}\end{array}$ & $\begin{array}{c}\text { IsoQ } \\
{[\mu \mathrm{g} / \mathbf{g ~ d w}]}\end{array}$ & $\begin{array}{c}\text { QUE } \\
{[\mu \mathrm{g} / \mathbf{g ~ d w}]}\end{array}$ & $\begin{array}{c}\text { MYR } \\
{[\mu \mathrm{g} / \mathbf{g ~ d w}]}\end{array}$ & $\begin{array}{c}\text { KAE } \\
{[\mu \mathrm{g} / \mathbf{g ~ d w}]}\end{array}$ & $\begin{array}{c}\text { L-7gl } \\
{[\mu \mathrm{g} / \mathbf{g ~ d w}]}\end{array}$ \\
\hline First & $548.2 \pm 3.3$ & $910.6 \pm 3.0$ & $826.5 \pm 3.5$ & $1638.4 \pm 4.6$ & ND & $432.5 \pm 2.7$ \\
Second & $320.4 \pm 3.2$ & $760.3 \pm 3.5$ & $780.7 \pm 3.1$ & $1054.0 \pm 4.0$ & ND & $248.8 \pm 3.3$ \\
Third & $280.0 \pm 2.6$ & $222.1 \pm 2.4$ & $650.7 \pm 2.1$ & $867.2 \pm 3.0$ & ND & $178.9 \pm 3.5$ \\
\hline
\end{tabular}

Values are expressed as means \pm standard deviation $(n=3)$; ND - not detectable Limit of detection for $\mathrm{KAE}-1.7 \mu \mathrm{g} / \mathrm{mL}$

Table 5. The antioxidant capacities of Cistus incanus multiple aqueous extractions evaluated by DPPH and FRAP assays.

\begin{tabular}{lcc}
\hline Extraction & $\begin{array}{c}\text { DPPH } \\
{[\mu \mathrm{mol} \mathrm{TE} / \mathbf{g ~ d w}]}\end{array}$ & $\begin{array}{c}\text { FRAP } \\
{\left[\mathrm{mmol} \mathrm{Fe}^{2+} / \mathbf{g ~ d w}\right]}\end{array}$ \\
\hline First & $82.5 \pm 1.8$ & $112.6 \pm 2.0$ \\
Second & $77.0 \pm 1.9$ & $100.3 \pm 1.4$ \\
Third & $72.6 \pm 1.0$ & $96.6 \pm 1.2$ \\
\hline
\end{tabular}

Values are expressed as means \pm standard deviation in $\mu \mathrm{g} / \mathrm{g} \mathrm{dw}$ $(\mathrm{n}=3)$; DPPH - 2,2-diphenyl-1-picrylhydrazyl radical; FRAP - ferric reducing/antioxidant power; $\mu \mathrm{mol} \mathrm{TE} / \mathrm{g} \mathrm{dw}-\mu \mathrm{mol}$ Trolox equivalent per gram dry weight; $\mathrm{mmol} \mathrm{Fe} \mathrm{F}^{2+} / \mathrm{g} \mathrm{dw}-$ mmol ion equivalents per gram dry weight

\section{Discussion}

The presented results demonstrate that systematic administration of aqueous extract of $\mathrm{Cis}$ tus incanus influences the lipid profile in healthy adults. According to available research, this is the first study to investigate any association between a serum oxidative stress biomarker and a Cistus incanus tea-rich diet. The in vivo studies of biological activity of polyphenols seem be especially important because polyphenols are extensively metabolized in the body and their bioavailability may be different. Thus, the relation between the quantity of polyphenols in food and their in vivo activity is not obvious [7, 21].

Excessive uncontrolled lipid and protein oxidation is associated with pathogenesis of various diseases such as atherosclerosis, osteoporosis, cancer, Alzheimer's, and Parkinson's diseases. Among them atherosclerosis is the underlying condition in most cardiovascular diseases being the leading cause of death in Western societies. Oxidation of LDLs is a key mechanism in this chronic systematic disease, leading to the development and progression of the disease. A number of animal studies have demonstrated that consumption of polyphenols limits the incidence of coronary heart disease and an abundance

Table 6. Minimal inhibitory concentration (MIC) and minimal bactericidal concentration (MBC) values of Cistus incanus multiple aqueous extracts against reference strain and clinical isolates.

\begin{tabular}{|c|c|c|c|c|c|c|c|}
\hline \multirow[t]{2}{*}{ Microorganisms } & \multirow[t]{2}{*}{ ATCC No. } & \multicolumn{3}{|c|}{$\mathrm{MIC}[\mathrm{mg} / \mathrm{mL}]$} & \multicolumn{3}{|c|}{$\mathrm{MBC}[\mathrm{mg} / \mathrm{mL}]$} \\
\hline & & $\begin{array}{c}\text { First } \\
\text { extraction }\end{array}$ & $\begin{array}{c}\text { Second } \\
\text { extraction }\end{array}$ & $\begin{array}{c}\text { Third } \\
\text { extraction }\end{array}$ & $\begin{array}{c}\text { First } \\
\text { extraction }\end{array}$ & $\begin{array}{c}\text { Second } \\
\text { extraction }\end{array}$ & $\begin{array}{l}\text { Third } \\
\text { extraction }\end{array}$ \\
\hline Staphylococcus aureus & 6538 & 4 & 4 & 4 & 8 & 8 & 8 \\
\hline $\begin{array}{l}\text { Methicillin-resistant } \\
\text { Staphylococcus aureus }\end{array}$ & 12673 & 4 & 4 & 4 & 32 & 32 & 16 \\
\hline $\begin{array}{l}\text { Staphylococcus } \\
\text { epidermidis }\end{array}$ & 14990 & 4 & 4 & 4 & 8 & 8 & 8 \\
\hline $\begin{array}{l}\text { Methicillin-resistant } \\
\text { Staphylococcus } \\
\text { epidermidis }\end{array}$ & 13199 & 4 & 4 & 4 & 16 & 16 & 16 \\
\hline $\begin{array}{l}\text { Streptococcus } \\
\text { pneumoniae }\end{array}$ & $\begin{array}{l}\text { Clinical } \\
\text { isolate }\end{array}$ & 4 & 4 & 4 & NA & NA & NA \\
\hline Bacillus subtilis & 6633 & 4 & 4 & 4 & 8 & 8 & 8 \\
\hline Escherichia coli & 8739 & NA & NA & NA & NA & NA & NA \\
\hline
\end{tabular}

ATCC - American Type Culture Collection; NA — no antimicrobial activity 
of literature has shown that polyphenols effectively protect LDL against oxidation ex vivo [4, $5,22]$. In the present study, assessing the effect of herbal supplements on oxidative stress parameters, it was found that the concentration of MDA as a marker of lipid peroxidation, and AOPP as a marker of protein peroxidation, decreased significantly after 6 weeks of use. Data in the literature concerning the impact of phenolic compounds from Cistus incanus extract on oxidative balance is poor. However, the increase in antioxidative capacity of plasma following the consumption of other polyphenol-rich food has been widely described. Litvinov et al. [23] showed that even a single dose of tea with or without milk increases plasma antioxidant activity. Increased antioxidative capacity was also observed as a consequence of the systematic intake of wine and beer, as well as fruit and vegetables rich in polyphenols such as strawberries and spinach [2]. It has also been shown that the consumption of polyphenol-rich blackcurrant and apple juice by healthy volunteers significantly reduced the plasma concentrations of MDA [24]. However, data from the impact of red wine consumption on lipid peroxidation is ambiguous [25-27].

Potent inhibition of LDL oxidation is, however, not only suggested by the protective effects of polyphenols against cardiovascular disease. Polyphenols have also been shown to inhibit the invasion and proliferation of smooth muscle cells in the arterial wall, inhibit platelet aggregation, and improve endothelial dysfunction in animal models $[28,29]$. Polyphenols may also modify the lipid profile. A significant increase in plasma HDL-C was observed in healthy adults when administered drinks containing coca for 12 weeks [30]. Administration of Bergamot polyphenol extract for 30 days also resulted in increased HDL-C and decreased triglyceride concentrations in hyperlipidemic patients [31]. Data from the study about rich-inpolyphenol teas are, however, contradictory. One meta-analysis found no effects of black tea on TC and serum concentrations of LDL-C and HDL-C [32], while another concluded that consumption of black tea lowered LDL-C, especially in subjects at high cardiovascular risk [33]. In the current study a significant increase in $\mathrm{HDL}-\mathrm{C}$ concentration was observed and a decrease in TG level during a 3-month supplementation with Cistus incanus was also recorded. These results suggest a positive impact on lipid metabolism and confirms a very wide range of potential pro-health attributes of Cistus incanus.
Several studies have attempted to elucidate the phenolic composition of Cistus incanus [34-37]. Viapiana et al. [20] in their earlier work assessed the phenolic profile and antioxidant capacity of aqueous extract of 15 commercially available samples of Cistus incanus, and showed that the place of the origin was the main factor in differentiating the Cistus incanus samples. The extracts obtained from Turkish Cistus incanus were the richest in total phenolic compounds (TPC), flavonoids (TFC), phenolic acid (TPAC) and ascorbic acid (AA). Cistus incanus used in the present study came from Mediterranean part of Turkey around the city of Antalya and - similar to previously analyzed samples from Turkish Cistus incanus - myricetin, quercetin, and isoquercetin were the most abundant phenolic compounds, with a content exceeding $800 \mu \mathrm{g} / \mathrm{g}$ dw. Gallic acid and rutin were found at the level ca. $500 \mu \mathrm{g} / \mathrm{g} \mathrm{dw}$, and 7-luteolin glucoside came in ca. $400 \mu \mathrm{g} / \mathrm{g} \mathrm{dw}$.

The antioxidant activities, evaluated with DPPH and FRAP also showed similar results to the previous published range of antioxidative capability of samples from Turkish Cistus incanus [20]. Deng et al. [38] determined the antioxidant capacities and total phenolic contents of 56 vegetables, and the levels of TPC, DPPH and FRAP values were lower than results obtained in this study, which seems to confirm Cistus incanus tea as a good source of polyphenols in the human diet. However, Konieczynski et al. [39] determined individual phenolic compounds in green and black teas and their total levels were higher than that obtained in the Cistus incanus infusions. In earlier studies it was established that aqueous extracts of Cistus exhibit good antimicrobial activity, particularly against bacteria $\mathrm{G}(+)$, and to a much lesser extent, affecting the growth of bacteria $\mathrm{G}(-)[20,37]$. Therefore, in this work it was decided to perform tests mainly in relation to selected $\mathrm{G}(+)$ bacteria. The present results confirmed good antimicrobial activity against bacteria $\mathrm{G}(+)$. Once again, no activity was demonstrated against $\mathrm{G}(-)$ bacteria in the tested concentration range.

According to the commercially included instructions, volunteers participating in the project reinfused the daily portion of Cistus incanus 3 times. The study of the multiple extractions effect on the phenolic acids and flavonoids content revealed that Cistus incanus tea can be re-infused; however, the first infusion showed higher levels of polyphenols and antioxidant activities, which 
gradually decreased in later infusions. There was no difference in antimicrobial activity of the extracts on successive infusions.

\section{Conclusions}

This study supports the idea that Cistus incanus tea can be a valuable source of polyphenols in the human diet. The supplementations with the commercially available Turkish Cistus incanus tea had a positive impact on oxidative stress markers and lipids profile, allowing us to suggest that there are a wide range of pro-health properties of Cistus incanus, and beneficial effects on the cardiovascular system may be added.

\section{Acknowledgements}

We would like to thank the Student Research Circle in Clinical Chemistry of Medical University of Gdansk for its help in the recruitment of participants and the realization of the project.

\section{Funding}

This work was supported the Ministry of Science and Higher Education Republic of Poland from the quality-promoting subsidy under the Leading National Research Centre (KNOW) program 2012-2017, Faculty of Pharmacy with Subfaculty of Laboratory Medicine [dec. MNiSWDS-6002-4693-23/WA/12] and Medical University of Gdansk grant no. 02-0125/07/524.

\section{Conflict of interest: None declared}

\section{References}

1. Barrajón-Catalán E, Fernández-Arroyo S, Roldán $\mathrm{C}$, et al. A systematic study of the polyphenolic composition of aqueous extracts deriving from several Cistus genus species: evolutionary relationship. Phytochem Anal. 2011; 22(4): 303-312, doi: 10.1002/pca.1281, indexed in Pubmed: 21259376.

2. Scalbert A, Manach C, Morand C, et al. Dietary polyphenols and the prevention of diseases. Crit Rev Food Sci Nutr. 2005; 45(4): 287-306, doi: 10.1080/1040869059096, indexed in Pubmed: 16047496.

3. Reis JF, Monteiro VV, de Souza Gomes R, et al. Action mechanism and cardiovascular effect of anthocyanins: a systematic review of animal and human studies. J Transl Med. 2016; 14(1): 315, doi: 10.1186/s12967-016-1076-5, indexed in Pubmed: 27846846.

4. Tressera-Rimbau A, Arranz S, Eder M, et al. Dietary Polyphenols in the Prevention of Stroke. Oxid Med Cell Longev. 2017; 2017: 7467962, doi: 10.1155/2017/7467962, indexed in Pubmed: 29204249.

5. Manach C, Mazur A, Scalbert A. Polyphenols and prevention of cardiovascular diseases. Curr Opin Lipidol. 2005; 16(1): 77-84, indexed in Pubmed: 15650567.
6. Oak MH, Auger C, Belcastro E, et al. Potential mechanisms underlying cardiovascular protection by polyphenols: Role of the endothelium. Free Radic Biol Med. 2018; 122: 161-170, doi: 10.1016/j.freeradbiomed.2018.03.018, indexed in Pubmed: 29548794.

7. Pandey KB, Rizvi SI. Plant polyphenols as dietary antioxidants in human health and disease. Oxid Med Cell Longev. 2009; 2(5): 270-278, doi: 10.4161/oxim.2.5.9498, indexed in Pubmed: 20716914.

8. Cutler BR, Petersen C, Anandh Babu PV. Mechanistic insights into the vascular effects of blueberries: Evidence from recent studies. Mol Nutr Food Res. 2017; 61(6), doi: 10.1002/ mnfr.201600271, indexed in Pubmed: 27558887.

9. Kalus U, Grigorov A, Kadecki O, et al. Cistus incanus (CYSTUS052) for treating patients with infection of the upper respiratory tract. A prospective, randomised, placebo-controlled clinical study. Antiviral Res. 2009; 84(3): 267-271, doi: 10.1016/j. antiviral.2009.10.001, indexed in Pubmed: 19828122.

10. MacKness B, Mackness MI, Durrington PN, et al. Paraoxonase activity in two healthy populations with differing rates of coronary heart disease. Eur J Clin Invest. 2000; 30(1): 4-10, indexed in Pubmed: 10619995.

11. Nakanishi M, Takanami Y, Maruyama T, et al. The ratio of serum paraoxonase/arylesterase activity using an improved assay for arylesterase activity to discriminate PON1(R192) from PON1(Q192). J Atheroscler Thromb. 2003; 10(6): 337-342, indexed in Pubmed: 15037822.

12. Yokode M, Kita T, Kikawa Y, et al. Stimulated arachidonate metabolism during foam cell transformation of mouse peritoneal macrophages with oxidized low density lipoprotein. J Clin Invest. 1988; 81(3): 720-729, doi: 10.1172/JCI113377, indexed in Pubmed: 3125226.

13. Witko-Sarsat V, Friedlander M, Capeillère-Blandin $\mathrm{C}$, et al. Advanced oxidation protein products as a novel marker of oxidative stress in uremia. Kidney Int. 1996; 49(5): 1304-1313, indexed in Pubmed: 8731095.

14. Singleton V, Orthofer R, Lamuela-Raventós R. [14] Analysis of total phenols and other oxidation substrates and antioxidants by means of folin-ciocalteu reagent. Methods in Enzymology. Academic Press. 1999; 299: 152-178, doi: 10.1016/s00766879(99)99017-1.

15. European Pharmacopeia. European Pharmacopoeia. 2002.

16. Polish Pharmacopoeia VI. pp. 150. Warsaw: Polish Pharmacological Society. 2002: 150.

17. Abdelmageed OH, Khashaba PY, Askal HF, et al. Selective spectrophotometric determination of ascorbic acid in drugs and foods. Talanta. 1995; 42(4): 573-579, indexed in Pubmed: 18966266.

18. Tuberoso C, Rosa A, Bifulco E, et al. Chemical composition and antioxidant activities of Myrtus communis L. berries extracts. Food Chemistry. 2010; 123(4): 1242-1251, doi: 10.1016/j.foodchem.2010.05.094.

19. Benzie IF, Strain JJ. The ferric reducing ability of plasma (FRAP) as a measure of "antioxidant power": the FRAP assay. Anal Biochem. 1996; 239(1): 70-76, doi: 10.1006/abio.1996.0292, indexed in Pubmed: 8660627.

20. Viapiana A, Konopacka A, Waleron K, et al. Cistus incanus L. commercial products as a good source of polyphenols in human diet. Industrial Crops and Products. 2017; 107: 297-304, doi: 10.1016/j.indcrop.2017.05.066.

21. Martínez-Huélamo M, Vallverdú-Queralt A, Di Lecce G, et al. Bioavailability of tomato polyphenols is enhanced by process- 
ing and fat addition: Evidence from a randomized feeding trial. Mol Nutr Food Res. 2016; 60(7): 1578-1589, doi: 10.1002/ mnfr.201500820, indexed in Pubmed: 26887966.

22. Khurana S, Venkataraman K, Hollingsworth A, et al. Polyphenols: benefits to the cardiovascular system in health and in aging. Nutrients. 2013; 5(10): 3779-3827, doi: 10.3390/nu5103779, indexed in Pubmed: 24077237.

23. Litvinov D, Mahini H, Garelnabi M. Antioxidant and anti-inflammatory role of paraoxonase 1 : implication in arteriosclerosis diseases. N Am J Med Sci. 2012; 4(11): 523-532, doi: 10.4103/19472714.103310, indexed in Pubmed: 23181222.

24. Young JF, Nielsen SE, Haraldsdóttir J, et al. Effect of fruit juice intake on urinary quercetin excretion and biomarkers of antioxidative status. Am J Clin Nutr. 1999; 69(1): 87-94, doi: 10.1093/ ajcn/69.1.87, indexed in Pubmed: 9925128.

25. Sharpe PC, McGrath LT, McClean E, et al. Effect of red wine consumption on lipoprotein (a) and other risk factors for atherosclerosis. Qjm. 1995; 88: 101-108.

26. Chopra M, Fitzsimons PE, Strain JJ, et al. Nonalcoholic red wine extract and quercetin inhibit LDL oxidation without affecting plasma antioxidant vitamin and carotenoid concentrations. Clin Chem. 2000; 46: 1162-1170.

27. Puddey IB, Croft KD, Abdu-Amsha Caccetta R, et al. Alcohol, free radicals and antioxidants. Novartis Found Symp. 1998; 216: 51-62; discussion 63, indexed in Pubmed: 9949787.

28. Karim M, McCormick K, Kappagoda CT. Effects of cocoa extracts on endothelium-dependent relaxation. J Nutr. 2000; 130 (8S Suppl): 2105S-2108S, doi: $10.1093 / \mathrm{jn} / 130.8 .2105 S$, indexed in Pubmed: 10917930.

29. Wollny T, Aiello L, Di To, et al. Modulation of haemostatic function and prevention of experimental thrombosis by red wine in rats: a role for increased nitric oxide production. Br J Pharmacol. 1999; 127: 747-755.

30. Baba S, Osakabe N, Kato Y, et al. Continuous intake of polyphenolic compounds containing cocoa powder reduces LDL oxidative susceptibility and has beneficial effects on plasma HDL-cholesterol concentrations in humans. Am J Clin Nutr. 2007; 85(3): 709-717, doi: 10.1093/ajcn/85.3.709, indexed in Pubmed: 17344491.
31. Mollace V, Sacco I, Janda E, et al. Hypolipemic and hypoglycaemic activity of bergamot polyphenols: from animal models to human studies. Fitoterapia. 2011; 82(3): 309-316, doi: 10.1016/j. fitote.2010.10.014, indexed in Pubmed: 21056640.

32. Wang D, Chen C, Wang Yu, et al. Effect of black tea consumption on blood cholesterol: a meta-analysis of 15 randomized controlled trials. PLoS One. 2014; 9(9): e107711, doi: 10.1371/ journal.pone.0107711, indexed in Pubmed: 25237889.

33. Zhao Y, Asimi S, Wu K, et al. Black tea consumption and serum cholesterol concentration: Systematic review and meta-analysis of randomized controlled trials. Clin Nutr. 2015; 34(4): 612-619, doi: 10.1016/j.clnu.2014.06.003, indexed in Pubmed: 24972454.

34. Petereit F, Kolodziej H, Nahrstedt A. Flavan-3-ols and proanthocyanidins from Cistus incanus. Phytochemistry. 1991; 30(3): 981-985, doi: 10.1016/0031-9422(91)85291-7.

35. Santagati NA, Salerno L, Attaguile G, et al. Simultaneous determination of catechins, rutin, and gallic acid in Cistus species extracts by HPLC with diode array detection. J Chromatogr Sci. 2008; 46(2): 150-156, indexed in Pubmed: 18366875.

36. Riehle P, Vollmer M, Rohn S. Phenolic compounds in Cistus incanus herbal infusions - Antioxidant capacity and thermal stability during the brewing process. Food Res Int. 2013; 53(2): 891-899, doi: 10.1016/j.foodres.2012.09.020.

37. Wittpahl G, Kölling-Speer I, Basche S, et al. The polyphenolic composition of cistus incanus herbal tea and its antibacterial and anti-adherent activity against streptococcus mutans. Planta Med. 2015; 81(18): 1727-1735, doi: 10.1055/s-0035-1557822, indexed in Pubmed: 26291656.

38. Deng GF, Lin Xi, Xu XR, et al. Antioxidant capacities and total phenolic contents of 56 vegetables. J Functional Foods. 2013; 5(1): 260-266, doi: 10.1016/j.jff.2012.10.015.

39. Konieczynski P, Viapiana A, Wesolowski M. Comparison of Infusions from Black and Green Teas (Camellia sinensis L. Kuntze) and Erva-mate (Ilex paraguariensis A. St.-Hil.) Based on the Content of Essential Elements, Secondary Metabolites, and Antioxidant Activity. Food Analytical Methods. 2017; 10(9): 3063-3070, doi: 10.1007/s12161-017-0872-8. 